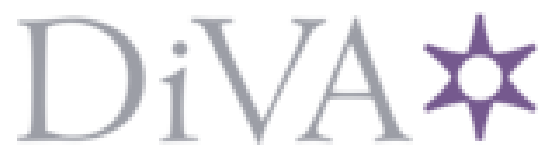

http://www.diva-portal.org

\title{
Postprint
}

This is the accepted version of a paper published in Konsthistorisk Tidskrift. This paper has been peerreviewed but does not include the final publisher proof-corrections or journal pagination.

Citation for the original published paper (version of record):

Jülich, S. (2015)

Lennart Nilsson's Fish-Eyes: A Photographic and Cultural History of Views from Below.

Konsthistorisk Tidskrift, 84(2): 75-92

http://dx.doi.org/10.1080/00233609.2015.1031695

Access to the published version may require subscription.

N.B. When citing this work, cite the original published paper.

Permanent link to this version:

http://urn.kb.se/resolve?urn=urn:nbn:se:uu:diva-256856 


\section{Lennart Nilsson's Fish-Eyes: A Photographic and Cultural History of Views from}

Below

Solveig Jülich, Department of History of Science and Ideas, Uppsala University, Box 629, 75126 Uppsala, Sweden, solveig.julich@idehist.uu.se

During his long and successful career the Swedish photographer Lennart Nilsson (born in 1922) has continuously demonstrated an interest in employing the latest visualization techniques for his work. Over the years he has made creative uses of advanced photographic and cinematic equipment coupled to various apparatuses such as scanning electron microscopes, ultrasound and computers. Probably his most unique imaging device, acquired around 1970, was a fish-eye lens with an angle of view of about 150 degrees, mounted at the end of a medical instrument called an endoscope, and connected to a camera (Fig. 1). This variant of wide-angle lens made it possible to create circular images of unusual width and depth that invited viewers to see things from an extreme upward-looking perspective. ${ }^{1}$ Specially designed at Nilsson's request, the fish-eye lens had a crucial part in the creation of many of the spectacular pictures of nature and the human body that established his international renown as a pioneer in scientific and medical photography. It also brought with it an aura of technological innovation and wizardry that still is associated with his name.

This article explores Nilsson's wide-angle imagery in its production and circulation contexts from the mid-1960s to the 1980s. It focuses in particular on a sample of photographs, labelled "fish-eye" because of the specific nature of their distorted perspective, which he produced for magazines, books and films during this period. The aim is to shed light on how these pictures helped to stimulate an alternative mode of spectatorship, the view from below, challenging the viewing position created by the traditional linear perspective of painting and photography. In common with some other extreme photographic perspectives, such as the bird's-eye views from balloons and aeroplanes, many of Nilsson's wide-angle pictures aspired to be all-embracing in their scope, to capture as much as possible of the visual world, but they did this from an upward-looking angle. What characterized this specific angle and how was it valued in relation to other visual modes and positions? Within what historical and cultural 
contexts did it emerge, how was it staged by the photographer and with what effects? As I will suggest, Nilsson's fish-eye photographs have been important in naturalizing a specific way of seeing life, in particular foetal life, in contemporary visual and media culture.

Earlier research on Nilsson has above all been dominated by feminist studies that have analysed the ideological content of his famous pictures of embryos and foetuses. Many scholars in this field have discussed these images as early instances of the construction of foetal personhood, i.e. the representation of the foetus as an autonomous individual with independent rights. They have also shown that American and British anti-abortion groups, from the early 1970s until today, have made extensive use of Nilsson's photographs in their claims for foetal protection. ${ }^{2}$ Less work has been done on his anatomical photographs of organs; the same applies to his nature pictures of insects, animals and plants. Overall, there is a lack of knowledge on how the photographs have been made, especially the imagery of human reproduction and its dependence on aborted foetuses, exacerbated by the reluctance of the photographer and his collaborators to discuss these issues. ${ }^{3}$ So far no studies have investigated how Nilsson's access to exclusive wide-angle lenses made it possible to launch the particular form of an all-embracing view from below in the first place, nor its cultural repercussions over the years.

To understand the history and mechanics of fish-eye optics this essay draws upon visual culture studies that have analysed the ways in which various visualization technologies and images have been claimed to place viewers in a privileged position to enable them to see things better. Many of these studies have been influenced by the concepts of the gaze and panopticon that Foucault used to characterize the self-disciplining mechanisms in traditional surveillance, borrowing from Jeremy Bentham's model of a panopticon prison. ${ }^{4}$ More recently, however, researchers have been cautious not to reduce the gaze to a narrow meaning but rather emphasize that the term comprises manifold ways of seeing that need to be defined historically and culturally. ${ }^{5}$ This insight has been developed in recent scholarship on how spectators were invited to experience - and themselves comment on - such visual spectacles as nineteenth century panoramas, early 
aerial photography, science museums as well as contemporary IMAX-theatres. ${ }^{6}$ Exploring the emergence of Nilsson's fish-eye imaging can help to distinguish an even larger palette of modes of looking and engagement. Inspired by the media theorists Jay David Bolter’s and Richard Grusin’s well-known concept of “remediation” I will discuss and contextualize how an immersive and transparent experience of Nilsson's fish-eye images could exist side by side with its apparent opposite: the hyper-mediated experience of the same type of image. ${ }^{7}$

In spite of the fact that Nilsson has had his laboratory at Karolinska Institutet, the prestigious Nobel-awarding medical university in Stockholm, practically no sources have been preserved that might be used to highlight his many years' work at this government institution. Nor have I had access to the company archives of Lennart Nilsson Photography AB or Bonnier, the photographer's principal publisher for more than half a century. To be able to carry out this study I have instead investigated a wide selection of sources that present and comment on the use by Nilsson and his contemporaries of wide-angle lenses, including everything from scientific publications and photographic literature to popular magazines and films. To supplement this method I have also conducted semi-structured interviews with the researchers and technicians that constructed the fish-eye lenses on Nilsson's behalf, as well as some of the TV producers he collaborated with. ${ }^{8}$

\section{A Cultural History of Fish-Eye Views}

Today wide-angle pictures taken with fish-eye lenses are associated with various uses, meanings and communities within visual media culture. Lomographs, who devote themselves nostalgically to old photographic techniques of dubious quality, have created magazines, books and forums on the web where they exhibit their fish-eye pictures and share tricks with each other. ${ }^{9}$ More commonly, "Fish-eye" is one of the standard effects that Mac users can play around with in the Photo Booth application which is also popular for iPhones. In addition, fish-eye optics are used in the peepholes of doors to give a wide visual field from the inside and at the same time obscure as much insight as possible from the outside. IMAX-theatres are equipped with fish-eye 
lenses, but they are also employed in scientific photography as a visualization tool to record for example clouds, polar lights and meteors. ${ }^{10}$

What characterizes fish-eye lenses is that they have a very large field of view of up to 180 degrees (some even larger). This is achieved by forgoing the production of images with straight lines of perspective and using instead a curvilinear construction that causes stretching at the edges of the images. As the name implies, fish-eye photographs have been considered to correspond to, or at least metaphorically allude to, how a fish with its globular eyes views the world. ${ }^{11}$ In contrast to humans, who also have a field of view of about 180 degrees, many fish have the ability to see clearly not only what is directly in front of them but also objects and movements on the periphery. ${ }^{12}$ But what the implications of fish-eye views are, in more precise terms, for the understanding of the particularities of the vision of fish or the general differences between animal, human and technological vision remain unclear. Current biological and zoological research on vision is targeted on both acquiring a better grasp of the superiority of animals' eyes and developing new technological applications by mimicking biological systems. ${ }^{13}$

Tracing contemporary fish-eye lenses back in history leads to a myriad beginnings and connections, including Renaissance maps offering all-embracing views of towns, optical dreams about creating the perfect lens as well as the "aquarium mania" of the nineteenth century. ${ }^{14}$ Most suggestive for this essay was the American physicist and inventor Robert Wood's experiment with a specially designed "fish-eye camera" conducted in the centre of Baltimore at the beginning of the twentieth century. His starting point was that while the human eye was badly adapted for vision under water, fish had a very wide field of vision. Fish that were swimming in a pond looking upwards towards the surface saw the whole sky as a clearly defined circle of light. Because of the refraction of the light this picture of a circle would also contain trees and other objects that were close to the pond; everything that was within an angle of 180 degrees. Trying to mimic how fish perceive humans he built a "miniature pond" made of a bucket impermeable to light with a camera submerged into clear water. This device was placed on the ground and a number of "very interesting pictures" were taken. 
One of the pictures was taken with nine men standing in a circle around the camera looking down at it while the exposure was made (Fig. 2). According to Wood this gave a good understanding of how fish swimming around in a pond or a river perceive humans. Another photograph was captured of the men when they were standing on a straight garden path with the camera placed close to the central figure and in a horizontal position instead pointing vertically upwards. In the picture the garden path appeared to be semi-circular and the figures furthest from the camera were distorted. This photograph would correspond to the way the visitors to an aquarium would appear to the fish. To get an all-embracing view of the city from above, the camera was placed at the top of The Washington Monument in central Baltimore. Wood did not mention, however, what kind of fish perception this bird's eyes view would correspond to. He imagined that his fish-eye camera could be used for practical purposes, for example in taking pictures of the sky, but this was to take another couple of decades. ${ }^{15}$

In the early 1920s the British bio-chemist Robin Hill introduced a new variant of Wood's fish-eye camera in which he had replaced the water by a spherical lens system. By aiming the device at the sky Hill could take pictures of different cloud formations and on one occasion he used two cameras to produce stereoscopic pictures. In spite of the attention this attracted among meteorologists, there was not enough interest to start commercial production of the camera. At the end of the 1950s Hill's method was rediscovered by plant physiologists, however, who for environmental purposes wanted to document the penetration of sunlight through the tree-tops in wooded areas. Within a few years sales of a complete camera equipped with Hill’s “whole-sky lens” manufactured by an English company had begun. ${ }^{16}$

This coincided with the launch by the camera manufacturer Nikon of a new wide-angle optic for the mass-market at the beginning of the 1960s that was labelled "fish-eye lens”. Other camera companies followed suit with new models and pictures taken with fish-eye lenses were for a time frequent in photo magazines for professionals as well as amateurs. The Swedish journal Foto for example printed a series of photographs captured by the well-known photographer Astrid Bergman-Sucksdorff that playfully demonstrated and commented on the characteristics of the new technology (Fig. 3). ${ }^{17}$ 
Perhaps Life magazine performed the most energetic role in marketing the special picture perspectives and creating awareness of the fish-eye lens in photo essays as well as advertisements. ${ }^{18}$

\section{Creating Views from Below}

Nilsson was one of the professional photographers who were interested in the fish-eye optics at an early stage. In the early 1960s he worked as a freelance photographer with assignments mainly for Bonnier, the largest media group in Sweden, and he had also published several photo books on everything from the life of ants to the Salvation Army. ${ }^{19}$ He was still occupied with his long-going project on documenting the development of the human foetus but had moreover started to photograph the inner organs of the human body. ${ }^{20}$ In a couple of years, Nilsson's photo essay "Drama of Life before Birth" in Life magazine was to attract worldwide attention and it was followed by his equally successful pregnancy guide Ett barn blir till (A Child Is Born). ${ }^{21}$

Interestingly enough Nilsson used new wide-angle lenses for all kinds of topics, scientific as well as more popular. For instance, in 1963 he used the new lenses from Nikon for a fashion report in Sergel's square and Nordiska Kompaniet's store in Stockholm. Obviously the possibility of offering an overview of architectural space and interiors was considered to be one of the attractions of the new technique (Fig. 4). ${ }^{22}$ But this lens was too big to be used inside the narrow cavities of the human body. Nilsson therefore sought the help of his technical assistant, the engineer and optical specialist Werner Donné, who altered existing lenses to produce a new lens system with an ultrashort focal length and an angle of view of 150 degrees. This minimal lens was mounted on endoscopes that could be inserted into the cavities of the body, surgical incisions or dissected organs. It was probably with this lens that Nilsson took the famous "portrait" of a 15-week-old foetus inside the womb, which was published in Life in $1965{ }^{23}$

Nilsson asked for lenses with an even wider angle of view and greater depth of field to be able to photograph inside blood vessels and other inaccessible parts within the body. During the latter part of the 1960s he contacted many different camera and optics companies, both in Sweden and in Germany, that he hoped would be able to construct a 
fish-eye lens with an angle of view of 180 degrees. ${ }^{24}$ Finally he managed to persuade Jungner Instrument AB in Stockholm to accept his order even though it was considered difficult to fulfil. After two years' work, in the spring of 1971, the company was able to deliver a fish-eye lens that had a focal length of $4 \mathrm{~mm}$ and an angle of view of 150 degrees, which was somewhat less than Nilsson had desired. The image itself was only $10 \mathrm{~mm}$ in size but could be enlarged up to 25 times without losing much definition. Using computers for the complicated optics calculations enabled the lens aberrations to be reduced to a minimum. Jungner made at least one more fish-eye lens for Nilsson. Regardless of how many really were involved, he seems to have been alone in owning lenses with these extreme properties. ${ }^{25}$

Nilsson's new visualization tool was presented in a 1971 issue of Sweden Now, a magazine published by trade and industry organizations with the aim of promoting Swedish science, industry and culture on a foreign market (Fig. 1). On one of the spreads a greatly magnified picture taken with the Jungner lens was claimed to visualize something that the human eye had never seen before. The picture showed a beetle in a pine forest that was threatened to be crushed by a walker whose shoe had assumed gigantic proportions. It was not only the extreme perspective that was held to be sensational but also the fact that the circular image captured "so much, so sharply, all at once”. To create this unusual picture Nilsson had placed the camera at ground level, beside the beetle, and pointed it upwards towards the walker in the forest. The camera was connected to an endoscope, an optical instrument designed for medical use, with the Jungner lens mounted at the end. ${ }^{26}$

Nilsson used his unique fish-eye lenses to produce multiple pictures of the micro-worlds of the human body and nature that were circulated in different media. The book Se människan [Behold Man], published in 1973, had the subheading "A Photographic Journey of Discovery inside the Body” and was marketed as a handbook in biology and anatomy to the general public. The picture material was varied and included everything from fertilization and foetal development to the tissues of the body, the metabolism, the nervous system and the sensory organs. ${ }^{27}$ Slightly more than 10 years later Nära naturen [Close to Nature] was published. Instead of a spectacular voyage through the 
body the readers were invited to take part in a journey into the invisible world around them in the seemingly familiar forests and meadows. In the different chapters pictures of flowers and bees and decomposition processes shared the pages with fossilized flowers and biting mosquitos. ${ }^{28}$ By describing both of the books as "voyages of discovery” in unknown lands Nilsson and his co-authors proclaimed their links to a long historical tradition of mapping projects in science and popular science. ${ }^{29}$

What characterized several of the pictures in these books was that they also - like the Renaissance maps of towns - showed "all-embracing views" of various scenarios and objects. $^{30}$ In Behold Man it was the small and narrow spaces in the inner organs and organ systems of the body that Nilsson had reproduced by means of endoscopes and wide-angle lenses. One of these circular pictures had been taken inside an eye and illustrated how the light refracted through the cornea and the lens to a point on the retina. Another of the pictures in the book showed the cavities of the inner ear. ${ }^{31}$ This kind of strategy was also applied in Close to Nature, for example in the cover photo of a caterpillar crawling across a railway track (Fig. 6). The caterpillar, the approaching train and the surroundings had all been caught by the fish-eye lens. ${ }^{32}$ These all-embracing views had a tendency to draw the viewer into the picture. They invited involvement in an immersive experience similar to the one Alison Griffiths has pointed to in her discussion of today's IMAX-theatres and their predecessors in the form of the panoramas and the science museums of the nineteenth century. ${ }^{33}$ Kärlekens mirakel [Life's Greatest Miracle], a film that was shown on Swedish and international television at the beginning of the 2000s, was significantly enough originally intended to be produced for IMAX as well, but for various reasons Nilsson and the producer Bo G. Eriksson were unable to do so. ${ }^{34}$

But the pictures also differed by imitating three different all-embracing viewing positions: one a perspective from above, one from the side and one from below. ${ }^{35}$ It is true that it is not always easy to decide how, or when it concerns the human body, where the pictures have been taken. Neither Behold Man nor Close to Nature gave particularly detailed technical data or other information. Besides, what is up and what is down in an inner organ is an open question. With these reservations it is still possible to 
highlight how Nilsson used the new wide-angle technique, with both Donné's and Jungner's lenses, to produce extreme and immersive viewing positions in human and animal environments.

The first viewing position, the from-above-perspective, was one Wood had already been experimenting with when he took his fish-eye camera to the top of the Washington Monument to get a view of central Baltimore. This elevated perspective is relatively rare in Nilsson's material, at least when it comes to motifs from the human body and the world of insects. The approach appears most clearly in a photograph taken with a Nikon lens in an operating theatre at Karolinska sjukhuset in 1963 (Fig. 5). The picture catches the scene with a patient suffering from Parkinson's disease from straight above. Here there are similarities with the bird's-eye view of maps and a great number of other general views. The special projection of the lens at the same time gave emphasis - like Konrad Morant's famous map of the town of Argentoratum (Strasbourg) engraved in 1548 - to the centre of the picture, which was the patient, while the surrounding doctors and nurses were forced out to the periphery. The picture must have been captured with a self-timer since the photographer is there too on the fringe of the picture. ${ }^{36}$ A couple of pictures of vocal chords, which were part of the section on breathing in Behold Man were also taken from above - from the oral cavity. ${ }^{37}$

The second viewing position - which according to Wood corresponded to the way fish in an aquarium see people - was the horizontal perspective. Many of the pictures taken from inside various organs and organ systems showed the subjects seen from the same level. A fellow journalist at a large magazine, Stig Nordfeldt, described in an article how the photographer worked in the autopsy room to produce these pictures of the inside of the body. In preparation for the photography session he had suspended an aorta taken from a deceased person. Several lamps were placed around the specimen, which gave it a warm, red tone. In order to take the picture he inserted an endoscope with Donné's lens mounted at the top and connected to a fibre optic light source. The miniature picture from the endoscope was then enlarged by means of another lens so that it covered the whole frame of the film in the camera. In this way the blood vessels 
could stand out as enormous tunnels with sharpness in detail over the entire field of view. $^{38}$

The third viewing position - which Wood said resembled the one of fish swimming in a pond looking straight towards the surface - was the from-below perspective. Many of the pictures in Behold Man used this perspective. This is for example true of a picture of the glottis and the vocal chords seen from below - a reversal of the perspective used in the pictures of vocal chords mentioned earlier. ${ }^{39}$ This approach had also been used when photographing the material for Close to Nature. One of the pictures showed the foliage of a maple tree from below, which was reminiscent of how further back the technique had been used by plant physiologists for scientific purposes. Nilsson also reused his idea from the report in Sweden Now mentioned earlier. On the cover there was a picture of a beetle in a forest that was about to be crushed under a hiker's boot. This picture, too, presented a position from below. ${ }^{40}$

If the elevated perspective has sometimes been described as a desire to adopt a god-like macro-cosmic position, then the perspectives from below and from the side can be seen as attempts to see the world from a micro-cosmic perspective. Several of Nilsson's nature photographs played with this idea, like for example the picture in Close to Nature that shows an earthworm tunnelling in the earth and the cover image of the caterpillar (Fig. 6). One of the first pictures taken with the new fish-eye technique showed a bumble-bee's view from inside a flower. ${ }^{41}$ To some extent this approach is similar to what James Elkins has tried to capture in his suggestive formulation "the object stares back”, by which he means the experience of being observed by an animal or an object whose existence we (humans) have not thought about before. ${ }^{42}$ Nilsson, however, also invites the viewer to picture how small and microscopic animals perceive the surrounding world as well as humans. Maybe this can even be interpreted as hinting at a moral view that sympathizes more with the inhabitants of the miniature world than the distant and isolated observer who has adopted a position of superiority. ${ }^{43}$

Among these pictures taken from below there are a couple of pictures that are perhaps the most remarkable ones in Nilsson's work. They are the photographs that present a 
perspective from inside the human body. An early example was the photograph on the cover of an issue of Life in 1968, which was the issue that contained the article "The Corridors of the Heart” (Fig. 7). The image had been taken from within the body with a living heart in the foreground and surgeons preparing to begin a heart operation in the background. Who the person was who had agreed to be photographed, or what the outcome of the operation was, the accompanying text did not say. ${ }^{44}$ In an article about the heart surgeon Viking Björk in a major Swedish daily paper in 1992 it was again a heart operation that gave Nilsson the opportunity to apply this extreme perspective. According to the caption, the camera had been aimed downwards, but by means of a prism the camera eye saw 90 degrees upwards. This meant that the photographer could "as it were sit in the middle of the heart and take pictures, in this case with a field of view of 160 degrees". In the background the surgeon and a mechanical cardiac valve that he was about to attach to the heart could be seen. ${ }^{45}$ Yet another example is one of the photographs in Kroppens försvar (The Body Victorious), a book on the immune system that was published in 1985, which showed the dentist's drill and the dentist seen from inside the mouth. ${ }^{46}$ In the film Life's Greatest Miracle Nilsson had arranged a scene with a couple kissing each other and one of the sequences was filmed from inside the woman's mouth. ${ }^{47}$

Who or what is it that watches from inside the body in these photographs? It is interesting to note an affinity between Nilsson's heart picture on the Life cover of 1968 and Stanley Kubrick’s films from the same period, which contained several scenes filmed with fish-eye lenses. This is especially true of 2001: A Space Odyssey (1968), where the intelligent computer HAL on board the spaceship Discovery was presented with the help of a fish-eye lens shining in red. HAL's voice and reactions were often followed by close-ups of the fish-eye with the effect that the computer appeared human. In A Clockwork Orange (1971) the director again used fish-eye lenses to show Alex' distorted perspective of reality. ${ }^{48}$ For Kubrick the special attraction of the technique seems, then, to have resided in its ability to conjure up visions that challenged established ideas about the borders between man and machine, hallucinations and reality, illness and health. Nilsson's picture in Life, too, questions our deep-rooted way of seeing; the viewer is invited to take the position of the heart and "stare back" at the 
surgeons who are about to cut into the body. The effect becomes equally eerie if we reflect instead on the fact that it is a camera lens that has been placed in the ventricle. The mechanically conveyed fish-eye view, which is thereby made possible, seems uncannily almost human.

Another article in a special issue on photography of Life in 1967, which contained several contributions by Nilsson, dealt explicitly with the nature of seeing with fish-eye technology as compared to fish vision and human sight. One of his photographs had been taken through the lens of a cod's eye and showed how a wrasse captured a stickleback. This unconventional image, using not fish-eye optics but "nature's lenses”, pretended to show how a (dead) fish sees two other fish in the water. The caption underlined the difference between the slightly rounded and adjustable human eye and the spherical and rigid character of the fish eye. Owing to its form the fish eye was said to see sharply only at short distances and since it could not accommodate, the lens must be moved backwards in the eye if it wants to focus on an object. Most fish have the eyes placed far from each other, which means that each eye sees a different picture.

According to the writer of the Life article there was probably a blind spot straight ahead and this could explain why some fish whirled round so much. Fish vision was less refined than human sight but it was also thought of as being undeveloped compared to visual technology. While a fish-eye camera had a field of view of 180 degrees, a fish was limited to between 50 and 60 degrees. In this context (and unlike Wood's theory), the vision of both humans and animals were disparaged and the fish-eye camera was hailed instead as a powerful extension and amplification of normal perceptual capabilities. ${ }^{49}$ The spectatorship from below offered by Nilsson's photographs was thus riddled with ambivalence: promising to place the viewer in a position to see the world from a privileged perspective, at the same time transforming the very conditions of seeing.

\section{Between Transparency and Hybridity}

In light of current interdisciplinary scholarship on the theoretical and historical interconnections of biology and technology, it seems important to reflect more on what kind of vision Nilsson's fish-eye lens laid claims to represent. ${ }^{50}$ A starting point for 
many of these academic discussions is Bruno Latour's thesis of a fundamental contradiction in what he calls "the modern constitution". According to him the ultimate paradox of the modern world is that while the proliferation of hybrids - mixtures of nature and culture - is allowed for, at the same time their very existence is denied. ${ }^{51}$ Following Latour's lead, Jay David Bolter and Richard Grusin have described media as hybrids and in their well-known work on "remediation" they distinguish between two dominant strategies of representation in Western visual culture. The first can be described as "transparency", a strategy to impart immediacy to the experience of the media content, and the second as "hypermediality" or "hybridity", which aims at making the viewer aware of the existence of the media. ${ }^{52}$ Drawing on these discussions I would like to highlight a similar tension in the presentation and discussion of fish-eye views. $^{53}$

Even Wood commented on the unusual view in the photographs taken with his fish-eye camera and felt called upon to defend them, perhaps not without a sense of humour:

While the views used for the illustration of this paper savour somewhat of the 'freak' pictures in the magazines, it is believed that the fact that they illustrate how one half of the world appears to 'the other half' is sufficient excuse for their publication. $^{54}$

The "freaks" that Wood alluded to were probably a kind of trick photograph popular around the turn of the century in 1900. By manipulating the exposure and the development of the photographic plates the dimensions of people and objects could be contorted playfully. Distorting mirrors in amusement parks were another contemporary medium based on distortion of the proportions of the body. ${ }^{55}$

Hill, too, who inspired by Wood built a "whole-sky camera" at the beginning of the 1920s, described the photographs of cloud formations that he took with this camera as in some respects problematic. With their inwardly curving lines these pictures were if not freaks then in any case strongly limited from a scientific point of view. Hill therefore tried to "normalize" the photographs "by reversing the action of the lens and placing a plate in the proper position to receive part of the image. Thus a part near the 
horizon can be converted into an ordinary view in which the horizon will appear as a straight line”. ${ }^{56}$ The photographs were hence corrected to look more like images taken with a standard lens while at the same time retaining panoramic qualities.

Nilsson's lenses had much in common with these scientific attempts to correct the distorted perspective of the optics. The ambition of the constructors at Jungner was to design a lens with a plane field of view, which made them approach the rectilinear perspective of a standard lens, and thereby minimize the distortion. This effort was in line with the strategy of transparency in that it emphasized the importance of a familiar photographic perspective for the viewer's acceptance of the image as a representation of the visual world. But many of the photographs Nilsson created with his wide-angle lenses were more akin to the strategy of hybridity. Like Bergman-Sucksdorff and other contemporary photographers he used the fish-eyes to produce a pyrotechnic display of sensational and surprising angles.

At the same time the strategies for different motifs were not chosen at random. This is particularly clear when one compares Nilsson's photographs of nature's micro-cosmos with the pictures that visualize the human being and in particular foetal development. In other words it is significant that the picture of the beetle in Sweden Now was described in terms of a spectacular effect created by the new camera lens. ${ }^{57}$ It is also typical that the photograph of a rhinoceros beetle in a blueberry thicket, which was included in Close to Nature, did not appear to make any claim to open a window on the surrounding world. The attraction of the picture, which was also emphasized in the captions, obviously consisted in the confusion of expected relations of form and size. ${ }^{58}$

These nature photographs may be compared with a foetus picture which was published in both Sweden Now 1976 and, a year later, in the second edition of A Child Is Born (Fig. 8). In the caption it was pointed out that the photograph taken with the unique Jungner lens had made it possible to visualize for the first time how the foetus lay enclosed in the womb. It was not taken from below (but then again, what is up and down in the context of the body). In other words, the caption together with the circular form of the fish-eye picture, worked together in drawing the viewer into the image and 
creating an impression of transparency: that the photograph showed a living foetus inside the body of a woman. ${ }^{59}$

Another foetal picture from the same series was reproduced in Jon Darius's collection of historical significant scientific photographs that was published in 1984. According to Darius this photograph documented a five-month-old "baby girl in the amniotic sac" using the photographer's pioneering endoscopic technique and special wide-angle lenses. ${ }^{60}$ While admitting that it was difficult to get information about the photographic details of this work, Darius nevertheless described it as one of Nilsson's "classic photographs of the human foetus in vivo". This was not the case, however. The foetus had been removed from a woman, who had been killed in a traffic accident, and then placed in a round bowl in the forensic laboratory where Nilsson took his pictures. ${ }^{61}$

Examples of this kind suggest that Nilsson's fish-eye photographs must be understood in their contemporary social and political contexts. To play with the established perspective in the world of nature photography does not seem to have aroused any strong reactions from his contemporary photographers or entomologists. On the whole reviews of Close to Nature in the daily press were positive and praised Nilsson's technical skills. ${ }^{62}$ The foetus pictures that were introduced during a period characterized by fierce debates on abortion, particularly in the United States, were on the other hand a potential source of conflict. Ever since the publication of "Drama of Life before Birth" in Life in 1965, the photographer's pictures had been used as weapons in the American pro-life movement. In the 1970s, this link with politically sensitive issues was something that Nilsson's publisher, Bonnier, wanted to avoid for commercial reasons. ${ }^{63}$ But moreover, even that most of his famous photographs showed dead foetuses that had been removed during surgical abortion procedures they had been presented as depicting living bodies. The illusionary or partly illusionary mastery to take pictures in vivo had allowed Nilsson to make a name as scientific photographer. ${ }^{64}$

The circular fish-eye picture of the dead five-month-old foetus in Sweden Now and the second edition of A Child Is Born was thus provided with deliberately vague captions which did not say exactly how it had been taken. The hybrid character of the picture 
was suppressed, in other words, and instead it appeared to be an unmediated view into the body, even for Darius, a specialist in the history of scientific instruments. Much later, in the 2003 edition of A Child Is Born, it was stated clearly that the image had been taken ex utero although the background history was not given. ${ }^{65}$

One could speculate on whether the fish-eye photographs are hybrids in the sense that Latour gives to the word. The depreciation of hybrids that he sees as characteristic of the modern constitution is echoed in the calls for correction of the unnatural, distorted perspective of fish-eye images. The production of Nilsson's fish-eye views of foetal life (or death) can also be understood as a Latourian purification process. But these positions must not be seen as either fixed or static. As I have discussed, the complex interactions between purification and mediation, or transparency and hybridity must be viewed in the light of the specific historical contexts in which the pictures were produced, marketed and circulated.

\section{The Naturalization of Fish-Eye Seeing}

This article has placed Nilsson's wide-angle photographs in wider historical and cultural circumstances. It has demonstrated in particular his use of improved and specially ordered fish-eye lenses to create all-embracing views of the micro-worlds of nature and the body. In a sense, these views may be said to constitute a panoptic vision or even an imperial quest to view and map unknown topographies, linking the photographs to a tradition of dominating the global world through two-dimensional representations. But importantly, they also differ in enabling not only a viewing position from above but also from below and from the side. As indicated, there is a moral to be read from some of these pictures in that the view from below is favoured over the god-like view from above. The insistence of the world-views of small and miniature beings is at the heart of Nilsson's moral vision. Still, the identity offered to the viewers of the pictures is far from unambiguous. They seem to tell us that we are something neither animal, nor human but, closer to HAL, a hybrid existence. 
To conclude, I wish to suggest that Nilsson's use of fish-eye lenses has served to promote a specific mode of viewing foetal development. As already discussed, he tended to stage the images of foetuses as inviting transparent and immersive experiences in contrast to the hyper-mediated experiences offered by pictures of insects, plants and flowers. This manoeuvre can be interpreted in the light of the feminist critique of Nilsson's foetal images mentioned at the beginning of this essay. Donna Haraway, Caroline Stabile and others have successfully demonstrated the working of ideological meanings through the pictures with the effect of naturalizing a way of seeing dead foetuses (as living individuals, persons, babies) and so as narrowing other interpretations. Yet several of these scholars as well as photographic specialists such as Darius have often taken the ex utero images for in vitro images, thereby unwittingly contributing to Nilsson's aura of heroic scientific and technological achievement. ${ }^{66}$ The use of endoscopes in combination with fish-eye lenses, which creates circular pictures, has worked to enforce the false impression that the instruments have been inserted into and documented foetuses inside the maternal body. In general, there has also been a tendency to overemphasize the photographer's role in the development of the visualization techniques involved in the making of these pictures. Nilsson did not invent or design endoscopes or optical lenses but he could afford to order this equipment and have a team of experts build or modify it on his request.

In sum, as a consequence of the photographer's extraordinary success in selling and circulating his foetal images, the former "abnormal” and "grotesque” fish-eye view came to be regarded (and, by feminists, criticized for their claim to act) as an authoritative, even scientifically objective, way of gaining access to and visualizing human reproduction. To put it differently, as the novelty of seeing with fish-eyes gradually faded it became more and more transparent and seemed like natural vision of foetal life empowered by cutting-edge visualization technology.

\section{Figures}

1. From Lennart Nilsson, “First Picture with the World's Deepest Widest Lens”, Sweden Now, Vol. 5, No 6, 1971. Courtesy of Lennart Nilsson/TT News Agency. 
2. From Robert Wood, “Fish-Eye Views, and Vision under Water”, Philosophical Magazine, Vol. 12, sixth series, August, 1906. Courtesy of Taylor \& Francis.

3. From Astrid Bergman-Sucksdorff, "Lek med Fish-Eye [Playing with Fish-Eye]”, Foto, No 9, 1963. Courtesy of Pia Gillsäter and Jens Sucksdorff.

4. From Ingeborg White and Lennart Nilsson, "Fränt, fräckt, fördomsfritt! [Groovy, cheeky and unprejudiced]”, Idun Veckojournalen, No 37, 1963. Courtesy of Lennart Nilsson/TT News Agency.

5. From Lennart Nilsson and Stig Nordfeldt, "Människor på sjukhus 1: 40 sekunder och ett nytt liv börjar [People in hospital 1: in 40 seconds a new life will begin]”, Idun Veckojournalen, No 46, 1965. Courtesy of Lennart Nilsson/TT News Agency.

6. From Lennart Nilsson, Nära naturen: En upptäcktsfärd i naturens mikrokosmos [Close to Nature: An Exploration of Nature’s Microcosm], Stockholm: Bonnier, 1984. Courtesy of Lennart Nilsson/TT News Agency.

7. The cover photograph by Lennart Nilsson for the story "The Corridors of the Heart" that was published in Life, 19 January, 1968. Courtesy of Lennart Nilsson/TT News Agency.

8. From Lennart Nilsson, “Life Before Birth”, Sweden Now, Vol. 10, No 5, 1976. Courtesy of Lennart Nilsson/TT News Agency. 


\section{Acknowledgments}

I would like to thank the Guest Editor Anna Orrghen and the anonymous referees of this journal for helpful commentaries on earlier versions.

Funding: This work was supported by the Swedish Research Council [Dnr 446-20141749].

\footnotetext{
${ }^{1}$ Lennart Nilsson, “First Picture of the World’s Deepest Widest Lens”, Sweden Now, Vol. 5, No 6, 1971, pp. 34-35. The caption states that the lens "has an angle of over $170^{\circ}$ " but in an article by one of the specialists involved in the production of the lens it is made clear that the angle was about 150 degrees. See Bo Möller, "Stor precision för litet objektiv [Great precision for a small lens]”, Forskning och framsteg, No 1, 1972, p.
}

4. All translations from Swedish in this essay are the author's own.

2 See, for instance, Donna Haraway,

Modest_Witness@Second_Millennium.FemaleMan@_Meets_OncoMouse:Feminism and Technoscience, New York: Routledge, 1997, p. 178; Sandra Matthews and Laura Wexler, Pregnant Pictures, New York: Routledge, 2000, pp. 195-198; Meredith W. Michaels, "Fetal Galaxies: Some Questions About What We See”, in Lynn M. Morgan and Meredith W Michaels, ed., Fetal Subjects, Feminist Positions, Philadelphia: University of Pennsylvania Press, 1999, pp. 113-132; Carol A. Stabile, "Shooting the Mother: Fetal Photography and the Politics of Disappearance”, Camera Obscura, No. 28, 1993, pp. 179-205. For a recent discussion on this feminist scholarship, see Julie Roberts, The Visualised Foetus: A Cultural and Political Analysis of Ultrasound Imagery, Abingdon: Ashgate Publishing Group, 2012, pp. 36-39.

${ }^{3}$ This is discussed in more detail in Solveig Jülich, “Lennart Nilsson’s A Child Is Born: The Many Lives of a Pregnancy Photo Book”, Culture Unbound, Vol. 7, 2015, pp. 627648.

${ }^{4}$ For a recent discussion, see Dag Petersson and Louise Wolthers, "Editorial”, Photographies, Vol. 7, 2014, pp. 1-10, on pp. 5-6.

${ }^{5}$ David Morgan, The Sacred Gaze: Religious Visual Culture in Theory and Practice, Berkeley: University of California Press, 2005, pp. 3-6. 
${ }^{6}$ Alison Griffiths has contributed with a rich study on immersive and interactive spectatorship in historical perspective, see her book Shivers Down Your Spine: Cinema, Museums, and the Immersive View, New York: Columbia University Press, 2008. For discussions on mediated and remediated god's eye views, see Mark Dorrian and Frédéric Pousin, ed., Seeing from Above: The Aerial View in Visual Culture, London: I.B. Tauris, 2013; Anders Ekström "Seeing From Above: A Particular History of the General Observer”, Nineteenth-Century Contexts: An Interdisciplinary Journal, Vol. 31, 2009, pp. 185-207; Jeanne Haffner, The View from Above: The Science of Social space, Cambridge, MA: MIT Press, 2013.

${ }^{7}$ Jay David Bolter and Richard Grusin, Remediation: Understanding New Media, Cambridge, MA: MIT Press, 1999.

${ }^{8}$ Recordings and transcripts of the interviews, conducted in 2008, are in the possession of the author. An interview with Nilsson (17 January, 2009) has not been included since, due to old age, he did not recall the details of these events.

${ }^{9}$ Michael Kuhle, ed., Lomo Fisheye Rumble in the Pond Photo Book, Vienna: Lomographic Society International, 2006.

${ }^{10}$ A useful compilation of applications is available at Wikipedia, "Fisheye lens", http://en.wikipedia.org/wiki/Fisheye_lens (accessed 21 January, 2015).

${ }^{11}$ Rudolf Kingslake, A History of the Photographic Lens, Boston: Academic Press, 1989, pp. 145-149.

${ }^{12}$ Michael F. Land and Dan-Eric Nilsson, Animal Eyes, Oxford: Oxford University Press, 2012, especially chapter 4.

${ }^{13}$ See the presentation of the research project "Ultimate Vision”, led by Dan-Eric Nilsson at Lund University, available at https://www.wallenberg.com/kaw/en/research/animal-eyes-inspire-new-cameratechnology (21 January, 2015).

${ }^{14}$ For an historical analysis inspired by a media archaeological perspective, see Solveig Jülich, “Images of Life and Death: The Lennart Nilsson Industry, 1940-2010” (working title for book manuscript, in progress).

${ }^{15}$ Robert Wood, “Fish-Eye Views, and Vision under Water”, Philosophical Magazine, Vol. 12, sixth series, August, 1906, pp. 159-162. 
${ }^{16}$ Robert Hill, “A Lens for Whole Sky Photographs”, Quarterly Journal of the Royal Meteorological Society, Vol. 50, 1924, pp. 227-235; G. D. Evans and D. E. Coombe, "Hemispherical and Woodland Canopy Photography and the Light Climate”, Journal of Ecology, Vol. 47, 1959, pp. 103-113.

${ }^{17}$ Astrid Bergman-Sucksdorff, “Lek med Fish-Eye [Playing with Fish-Eye]”, Foto, Vol. 25, No 9, 1963, pp. 48-53.

${ }^{18}$ See for instance the photograph of astronaut John Glenn in mock space capsule by Ralph Morse in Life, 27 January, 1961, p. 40, and the advertisement for Ford Motor Company in Life, 30 April, 1965, p. 71.

${ }^{19}$ Lennart Nilsson and Carl H. Lindroth, Myror [Ants], Stockholm: Forum, 1959;

Lennart Nilsson and Thorsten Kjäll, Halleluja: En bok om Frälsningsarmén [Halleluja: A book about the Salvation Army], Stockholm: Bonnier, 1963.

${ }^{20}$ Solveig Jülich, “Picturing Abortion Opposition in Sweden: Lennart Nilsson’s Early Photographs of Embryos and Foetuses”, Social History of Medicine, forthcoming 2016. ${ }^{21}$ Lennart Nilsson and Albert Rosenfeld, “Drama of Life before Birth,” Life, 30 April, 1965, pp. 54-72A; Lennart Nilsson, Axel Ingelman-Sundberg, and Claes Wirsén, Ett barn blir till: En bildskildring av de nio månaderna före födelsen: En praktisk rådgivare för den blivande mamman [A child is born: The Drama of Life before Birth in Unprecedented Photographs: A Practical Guide for the Expectant Mother] (Stockholm: Bonnier, 1965). For a recent analysis, see Solveig Jülich, “The Making of a Best-selling Book on Reproduction: Lennart Nilsson’s A Child Is Born”, Bulletin of the History of Medicine, Vol. 89, No 3, 2015, 491-525.

${ }^{22}$ Lars Öhngren and Lennart Nilsson, “Ingen kan hejda Kalderéns! [Nobody can stop Kalderéns!]”, Idun Veckojournalen, No 33, 1963, pp. 10-11; Ingeborg White and Lennart Nilsson, "Fränt, fräckt, fördomsfritt! [Groovy, cheeky and unprejudiced!]”, Idun Veckojournalen, No 37, 1963, pp. 27-29

${ }^{23}$ Nilsson and Rosenfeld, 1965, pp. 54-72A.

${ }^{24}$ Stig Nordfeldt, "Lennart Nilsson - fotografen som är en kamera [Lennart Nilsson the photographer who is a camera]”, Idun Veckojournalen, No 12, 1967, pp. 24-34; Lennart Nilsson, “Objektiv för trånga blodkärl [Lenses for narrow arteries]”, Forskning och framsteg, No 1, 1972, p. 3. 
${ }^{25}$ Möller, 1972, p. 4; Jackie Lindeberg, “Lennart Nilsson visar sitt nya mirakelobjektiv: Från humlan till oändlighet [Lennart Nilsson displays his new miracle lens From a bumble bee to infinity]”, Se, No 34, 1974, pp. 36-39. See also the interview with Bo Möller, 27 November, 2008, and 2 December, 2008.

${ }^{26}$ Nilsson, 1971, pp. 34-35.

${ }^{27}$ Lennart Nilsson and Jan Lindberg, Se människan: En fotografisk upptäcktsfärd i din kropp [Behold Man: A Photographic Journey of Discovery Inside the Body],

Stockholm: Bonnier, 1973.

${ }^{28}$ Lennart Nilsson, Nära naturen: En upptäcktsfärd i naturens mikrokosmos [Close to

Nature: An Exploration of Nature’s microcosm], Stockholm: Bonnier, 1984.

${ }^{29}$ Solveig Jülich, “Colouring the Human Landscapes: Lennart Nilsson and the

Spectacular World of Scanning Electron Micrographs”, Nuncius, 2014, Vol. 29, pp. 464-497.

${ }^{30}$ Lucia Nuti, “Mapping Place: Chorography and Vision in the Renaissance”, in Denis

E. Cosgrove, ed., Mappings, London: Reaktion, 1999, pp. 90-108.

${ }^{31}$ Nilsson and Lindberg, 1973, pp. 182-183 (the eye), p. 215 (the ear).

${ }^{32}$ Nilsson, 1984, front cover.

${ }^{33}$ Griffiths, 2008, especially chapter 3.

${ }^{34}$ Interview with Bo G. Erikson, 15-16 December, 2008.

${ }^{35}$ On the first of these viewing positions, see Ekström, 2009, pp. 185-207.

${ }^{36}$ Lennart Nilsson and Stig Nordfeldt, "Människor på sjukhus 1[People in hospital 1]”, Idun Veckojournalen, No 46, 1965, pp. 18-23.

${ }^{37}$ Nilsson and Lindberg, 1973, p. 87. On Morant's map, see Louis Marin, On Representation, Stanford: Stanford University Press, 2001, pp. 211-218.

${ }^{38}$ Lennart Nilsson and Stig Nordfeldt, “Åldrandets drama [The drama of ageing]”, Veckojournalen, No 40, 1967, pp. 28-31, 46.

${ }^{39}$ Nilsson and Nordfeldt, 1967, p. 87.

${ }^{40}$ Nilsson, 1984, cover and p. 31.

${ }^{41}$ Nilsson, 1984, p. 48; Forskning och framsteg, No 1, 1972, cover.

42 James Elkins, The Object Stares Back: On the Nature of Seeing, San Diego: Harcourt Brace, 1997, especially chapter 2. 
${ }^{43}$ On the moral implications of an elevated perspective, see Ekström, 2009, pp. 196197, 204.

${ }^{44}$ Lennart Nilsson, “The Corridors of the Heart” Life, 19 January, 1968, pp. 22-31.

${ }^{45}$ Kerstin Hellbom and Lennart Nilsson, "Klaffkampen [Valve battle]”, Dagens Nyheter, 27 September, 1992.

${ }^{46}$ Lennart Nilsson, Kroppens försvar: En bilderbok om hoten mot kroppen och hur kroppens immunförsvar fungerar [The Body Victorious: The Illustrated Story of Our Immune System and Other Defences of the Human Body], Stockholm: Bonnier, 1985, p. 159.

${ }^{47}$ Kärlekens mirakel [Life's Greatest Miracle], written by Bo G. Erikson and Julia Cort. First broadcast in Swedish Television in 2000.

${ }^{48}$ Stanley Kubrick, 2001: A Space Odyssey (1968) and Clockwork Orange (1971).

${ }^{49}$ Lennart Nilsson, “Nature’s Amazing Lenses”, Life, 23 December, 1966, pp. 22-31.

${ }^{50}$ For a survey of these discussions, see Jussi Parikka, Insect Media: An Archaeology of Animals and Technology, Minneapolis: University of Minnesota Press, 2010.

${ }^{51}$ Bruno Latour, We Have Never Been Modern, New York: Harvester Wheatsheaf, 1993.

52 Bolter and Grusin, 1999. In a later paper Bolter uses the term "hybridity” instead of "hypermediality”, see “The Desire for Transparency in an Era of Hybridity”, Leonardo, Vol. 39, No 2, 2006, pp. 109-111.

${ }^{53}$ Cf. Mette Bryld and Nina Lykke, "Bevisets teater: Videnskabsdokumentargenren og læsninger af Lennart Nilsson [The Theatre of Proof: The Science Documentary Genre and Readings of Lennart Nilsson]”, Polhem, 2004, pp. 90-108. Bryld and Lykke do not discuss fish-eye lenses per se.

${ }^{54}$ Wood, 1906, quotation on p. 162.

${ }^{55}$ See for instance some of the photographs published in Scientific American that were collected in Albert A. Hopkins, ed., Magic: Stage Illusions, Special Effects and Trick Photography, New York: Munn, 1897. It is not unlikely that Hill also alluded to the social documentary photography book by Jacob A. Riis, How the Other Half Lives: Studies Among the Tenements of New York, New York: Charles Scribner's Sons, 1890. 
${ }^{55}$ See for instance some of the photographs published in Scientific American that were collected in Albert A. Hopkins, ed., Magic: Stage Illusions, Special Effects and Trick Photography, New York: Munn, 1897.

${ }^{56}$ Hill, 1924, pp. 232-233.

${ }^{57}$ Nilsson, 1971, pp. 34-35.

${ }^{58}$ Nilsson, 1984, back endpaper.

${ }^{59}$ Lennart Nilsson, “Life before Birth”, Sweden Now, Vol. 10, No 5, 1976, pp. 34-35;

“Through a Unique Lens”, Sweden Now, Vol. 10, No 5, 1976, p. 79; Lennart Nilsson, Ett barn blir till: En bildskildring av barnets tillblivelse före födelsen och praktiska råd när man väntar barn [A Child Is Born: New Photographs of Life before Birth and Upto-Date Advice for Expectant Parents], 2nd edition, Stockholm: Bonnier, 1976, p. 121. ${ }^{60}$ Jon Darius, Beyond Vision: One Hundred Historic Scientific Photographs, Oxford: Oxford University Press, 1984, pp. 14, 120-121.

${ }^{61}$ This was described in an interview with the photographer and TV producer Carl O. Löfman, conducted in 19 December, 2008, who collaborated with Nilsson in the period. ${ }^{62}$ Bengt Hubendick, "Mikrokosmos och tropikerna [Microcosmos and the tropics]", Göteborgs-Posten, 30 November, 1984; Nils-Erik Landell, “Nya sätt att se [New ways of seeing]”, Svenska Dagbladet, 23 November, 1984.

63 Solveig Jülich, “Fetal Photography in the Age of Cool Media”, in Anders Ekström et al, History of Participatory Media: Politics and Publics, 1750-2000, New York: Routledge, 2011, p. 131.

${ }^{64}$ For a detailed analysis on the sources and methods of the images as well as how they were publicly presented, see Solveig Jülich, “Photographing Life before Birth: Lennart Nilsson and Reproductive Research in Post-War Sweden” (paper manuscript, in progress).

${ }^{65}$ Lennart Nilsson and Lars Hamberger, Ett barn blir till [A Child Is Born], 4th edn, Stockholm: Bonnier, 2003, p. 236

${ }^{66}$ Several scholars have mistaken the ex utero photograph on the famous cover of Life magazine in 1965 for an image captured by an endoscope inserted into the body of a pregnant woman. See, for instance, Haraway, 1997, p. 178; Matthews and Wexler, 2000, p. 195; Michaels, 1999, p. 117; Stabile, 1993, p. 185. Inside the magazine there was however Nilsson's only published endoscopic image of an embryo or foetus from 
the 1960s. Given the scarce information about how his images have been made this misunderstanding is understandable. 